\title{
Socio-Economic Condition of Indigenous Students: A Study in the University of Dhaka
}

\author{
Sumy Akter (Corresponding author) \\ Department of Social Work, Shahid Begum Seikh Fazilatunnesa Mujib Govt. College, \\ Ministry of Education, People's Republic of Bangladesh, Dhaka-1000, Bangladesh \\ E-mail: sumyakter_iswr@yahoo.com
}

Received: December 7, 2016

Accepted: January 7, 2017 Published: January 9, 2017

doi:10.5296/ijsw.v4i1.10416

URL: http://doi.org/10.5296/ijsw.v4i1.10416

\begin{abstract}
The participation rate of the indigenous people in higher education is comparatively low. In this work the socio-economic status of the indigenous students of the University of Dhaka is studied. Moreover, the problems and prospects of the students during their academic life in the university as well as in their social life are identified. This research is a social research in which a sample survey method has been taken. Mainly different residential Halls of the University of Dhaka were taken as the area of this research. Information was collected from 45 selected respondents. Data are collected through interviewing and observing respondent as well as from the secondary sources. Based on this research the problems of the indigenous students are identified. Beside these, a list of recommendations has been suggested to solve the socio-economic situation and problems in their academic life of the indigenous students. This study will help us to find out the impact of the family tradition on the present status of the indigenous students, barrier in exercising their traditional culture, and the attitude showed by the other students to the indigenous students in the University of Dhaka.
\end{abstract}

Keywords: Aboriginal people, Indigenous students, University of Dhaka, Ethnic groups

\section{Introduction}

All the present and complex cultures of the world are built up on a mixture of memories of the prehistoric and proto-historic aboriginal or tribal cultures (Maloney, 1984, Khaleque, 1998). The Indian sub-continent has a history of being a colony for as long as two hundred years under the British rule (A History of Bangladesh, 2009). In that period, the closed and conservative society and culture of this region has seen many changes and shifts. Many of the changes in economy, society, cultures, religion and social structure were not intentional but grown up with the structural changes occurring in the political and social sphere. New way of life and new classes emerged as a result of these changes. 
In the colonial period, and after that time, many ethnic tribal groups, currently known as Indigenous peoples have migrated and spread over the vast plain areas of the regions of India and Bangladesh (Baral, 2004). According to 2001 census, the estimated total tribal population of the Bangladesh was about 1.3 million, $1.06 \%$ of the national population. This becomes over 2 million in 2010 (BBS, 2014). The tribal people of the country generally prefer to be known variously as indigenous aboriginal peoples, Adibasis or Hill tribal people, and most of them are ethnic religious and ethnic minorities (Barkat, 2006).

However, there are approximately 45 aboriginal groups in Bangladesh (Sanders, 1999). They live primarily in the Chittagong Hill Tracts and in the regions of Mymensingh, Shylet and Rajshahi. The majority of the tribal population lives in the rural settings, where most of them practice the shifting cultivation. Most tribal people are of Sino Tibetan descent and have distinctive mongoloid appearance. They differ in their social organization, marriage, birth rights, food, and their social customs are different from the people of the rest of the country (Miller, 2000).

The participation rate of the Indigenous people in the higher education sector is disparately low. The pivotal role of the university sector in addressing the inequity and in releasing the potential for increase in Indigenous enrolment, participation and completion in higher education was studied by some researchers (Andersen, 2008). There are a number of barriers for the Indigenous students in their educational institute (Malcolm, 2002). They suggested some solution to assist the Indigenous students to overcome these barriers to improve their completion rate at the university. Conway marked emotional and behavioral disorder as a strong barrier in completing secondary education (Conway, 2006). Some also suggested science and technology based education with some revision of education policy in order to ensure the sustainable development of Bangladesh (Alam, 2009). Factors that might influence the disproportionate over-representation of Indigenous people are discussed by Graham (2012). The factors responsible for the low attainment were also studied by Haque (2000). The indigenous students are challenged by the financial hardship, staff insensitivity and discrimination to the cultural issues, lack of Indigenous mentors, poor study skills, lack of adequate educational preparation, lack of resources and ongoing family commitments (Usher et al., 2005).

\section{Significance of the Research}

The aboriginal people are living in their ancestral land in Bangladesh with their distinct languages, cultures, heritages, religions, diverse tradition and customs as well as with their own life style harmoniously for a long time (Roy, 2000). The daily life style of the indigenous people have inborn deep relationship with the forest, rivers, hills and valleys, land and nature (Besra, 2007). By the course of human history and due to heavy burden of modern civilization some aboriginal people now-a-days have adopted modern culture. They are coming to Dhaka, the capital city of Bangladesh, from their ancestral lands for improving themselves. Though, they are trying to cope up with the original Bengali society, but they can't perform properly with the highly diversified customs, culture, and religion of the original Bengali society. 
According to the report of the CARITAS, a non-government organization, the rate of education among the aboriginal people is increasing day by day. As a result, every year a remarkable number of students are admitted into different educational organization including the University of Dhaka. Since these aboriginal students have a very different language, distinct physical features, a totally different culture, and a unique life style, they can't practice their traditional way of life style in the main stream of the society. So they compete to cope up with the Bengali culture and society. Although many of them are living in the Bengali society for a long time, they are also confronting with many difficulties. Actually, many of these aboriginal students are now living in a quite different atmosphere from that of their ancestral land. So they are in many cases exploited and discriminated in the university area. So the present study is to deeply observe the problems of the indigenous students of the University of Dhaka.

\section{Objectives of the Research}

Because of the indigenous students come to the University of Dhaka from different types of culture, it is necessary to have clear idea about their cultures, so that the authority can take necessary steps to reduce their problems. The aims of this research were to study the socio-economic situation, to identify different problems of the indigenous students, and to recommend some solutions of these problems. This study will help us to find the impact of the family tradition on the present status of the Aboriginal indigenous students, to find out the barriers in exercising their culture in the University of Dhaka, and the attitude of the other students toward the indigenous students. The discrimination about giving facilities by the university authority was also discussed. Finally, some recommendations are made to improve their socio-economic condition of the Aboriginal indigenous students of the University of Dhaka.

\section{Methodology of the Research}

This research is a social research to explore facts. A sample survey method has been taken as the methodology of this research. Several residential Halls of University of Dhaka for example Jagannath Hall, Ruqayyah Hall, Bangladesh-Kuwait Maitree Hall, Shamsunnahar Hall and Bangamata Sheikh Fazilatunnesa Mujib Hall have been selected as the area of the study. As the number of Aboriginal students is not so many in the University of Dhaka, 45 Aboriginal indigenous students were taken as respondents of this research, also students of other groups are considered as participants. Information was collected from every selected respondent. Data were collected through interviewing and from the results what were asked to the respondents as well as from the secondary sources such as documents, literature, text books, journals, etc.

\section{Results of the Research}

There were 45 respondents in our research. Among them 56\% were male and $44 \%$ were female. This study shows that the age limit of the Aboriginal students who were studying in the University of Dhaka were 18-27 years. Most of them were between $22-24$ years old, of which $33 \%$ were 22 years old, $18 \%$ were of 23 years and $16 \%$ were of 24 years old. Apart 


\section{Macrothink}

International Journal of Social Work

ISSN 2332-7278

2017, Vol. 4, No. 1

from these $16 \%$ of the student's age was 20 years. Rest $11 \%$ respondents were form the age group of 18, 25 and 27 years. Summarizing the above data, it was assumed that there is no difference between the Aboriginal indigenous student and student of other groups in terms of age.

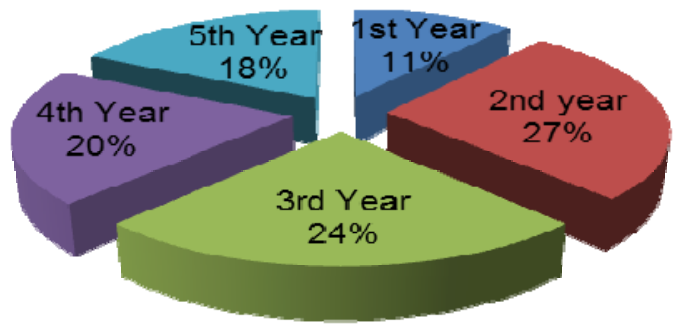

Figure 1. Educational qualification of the respondents

Data about the studying year for the correspondents is presented in Figure 1. Among the respondents more than $51 \%$ were studying in the $2^{\text {nd }}$ and $3^{\text {rd }}$ year, among them $27 \%$ were studying in the $2^{\text {nd }}$ year, $24 \%$ are studying in the $3^{\text {rd }}$ year. Only $11 \%$ of the respondents were from the $1^{\text {st }}$ year, whereas $20 \%$ were from the $4^{\text {th }}$ year and $18 \%$ from the $5^{\text {th }}$ year (Masters).

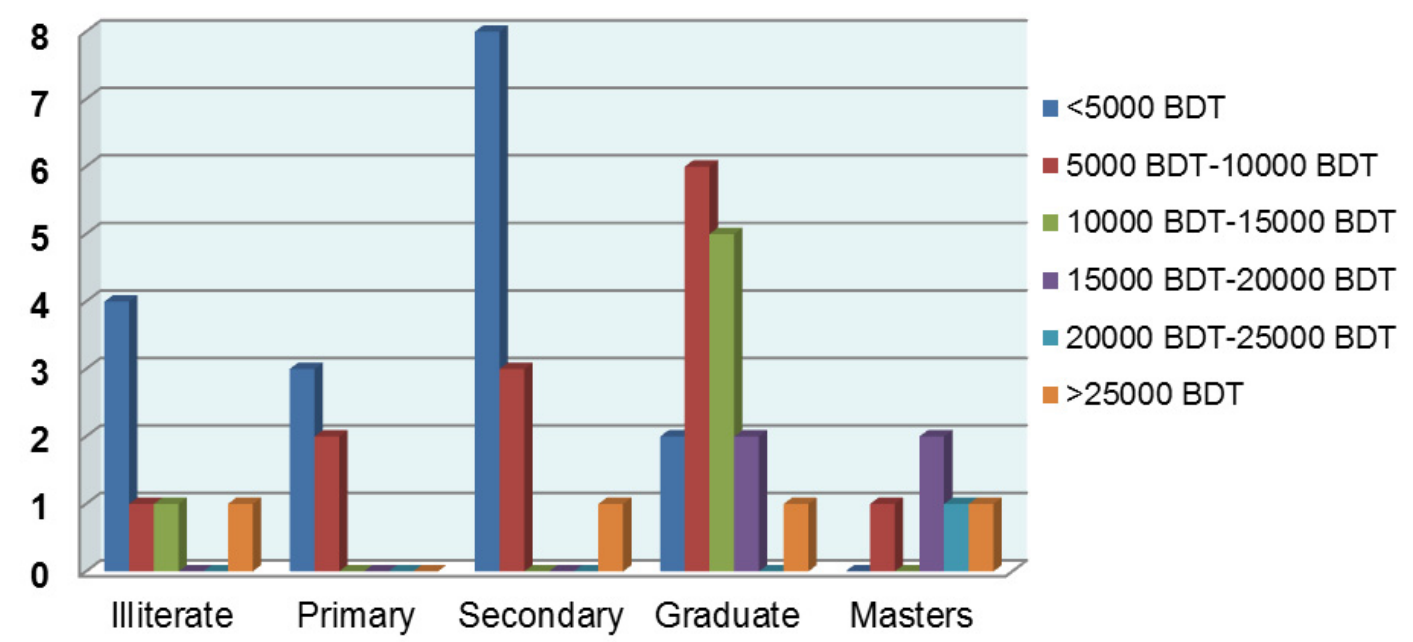

Figure 2. Income and education of the family head of the aboriginal indigenous students

The income of the family head of the aboriginal students has a great influence on their lifestyle. This study shows that the respondents whose family head had income $\leq$ BDT 5000 is 17 in number as shown in Figure 2. Among them 4 persons were illiterate, 3 persons completed their primary education, 8 persons completed secondary education and 2 persons 


\section{Macrothink}

were graduate, but there was no family head found in this income group who completed Masters degree. There are 13 family head found whose income level were BDT 5000-10000. Among them only one person found who was illiterate and one person found who completed Masters, 2 persons completed primary education, 3 persons completed secondary education and 6 persons were graduated. There were 6 family heads found whose income level were BDT 10000-15000. Among them only one person found who was illiterate and 5 persons completed graduation, but there was no family head from other education level. There are 4 family heads found whose income level were BDT 15000-20000. Among them 2 persons completed graduation and 2 persons completed Masters. Only one family head from BDT 20000-25000 income level completed Masters. There were 4 family heads found whose income were more than BDT 25000. Among them one person was illiterate and one person found from each education level of education.

It is also observed that income of the 17 respondent's family heads were less than BDT 5000. Among them 14 were farmer, 1 was housewife, whereas 2 persons were engaged in some sort of service. Among BDT 5000 - 10000 income level group 8 persons were servicemen, 3 persons were businessmen and 2 were farmer. Among BDT 10000 - 15000 income level group 2 persons are businessman and 4 persons were service holder. In the BDT $150000-$ 20000 income level group 2 persons are servicemen, 1 was farmer and 1 person was businessman. The family head who has income level BDT $20000-25000$ was found to bea serviceman and among the 4 family heads earning more than BDT 25000, 2 persons were farmer and 2 were doing job.

There were no Muslims among the respondents, and 18\% respondents were Christian, 6\% were Hindu and $76 \%$ respondents were Buddhist. Among these respondents only $56 \%$ could play their religious works, whereas $44 \%$ could not do the same. It was observed that most of the Christians could play their religious works and the percentages of such groups were $87 \%$, whereas it was $67 \%$ and $47 \%$ for Hindu and Buddhist, respectively. The mean of the religious activities was calculated to be 1.44 . It was found that the respondents who could not play their religious work are because of the lack of the religious institutions in the university area.

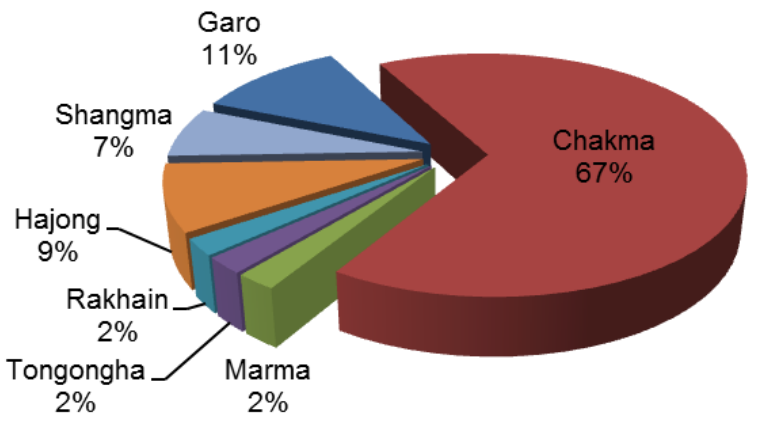

Figure 3. Names of the communities

The groups of communities among the respondents are shown in Figure 3. It was observed 
that maximum students came from the Chakma community. The percentages of that community among the respondents were $67 \%$, whereas $11 \%$ were Garo. Among the respondents Marma, Rakhain, Hajang, and Shangma were very few. It was observed that maximum respondents (67\%) were come from Rangamati and Khagrachari. Among the rest $11 \%$ respondents were from Bandarbans, $7 \%$ from Tangail, $5 \%$ from Chittagong, $4 \%$ from Moulovibazar, and 2\% from Borguna, Netrokona or Dinajpur.

Most of the respondents (about 76\%) mentioned about facing various problems when they tried to reside themselves in the university residential halls, while $24 \%$ respondents said about smooth entrance for their seat in the university residential halls. While studying the attitude of the normal students towards the aboriginal groups it was noted that about $49 \%$ respondents received good attitude from the other students, whereas $31 \%$ respondents considered others attitude as mediocre and $20 \%$ as satisfactory. None of the respondents reported about getting ruthless attitude from the others residential students in the university halls. Most of the respondents complained about assistance from the hall authorities. The percentage of this group is $96 \%$, whereas $4 \%$ respondents told that the hall authorities were helpful.

Usually, the Aboriginal students like to take some traditional food which has different smell or they follow different recipes to cook their food which are far from those of the other Bangladeshi food. A portion of the respondents reported that they did not face any problem in taking their traditional food in their own lodging premises. But they had to face problems while staying in their residential halls, though some respondents reported that they were able to take their traditional food cooking by themselves. Students of the other groups complain about their food types and food habits. The percentage of respondents who faced problem to take their traditional food was $44 \%$, on the other hand $56 \%$ respondent did not face any problem in food at all.

Usually some of the students are engaged themselves in different part-time job during their student life. But from this study it was observed only $22 \%$ respondents got opportunities to have part-time jobs, but $78 \%$ of them do not had any opportunity to get any part time job during their university life.

Though $93 \%$ of the respondents told that they do not feel insecure in the campus area, the rest $7 \%$ respondents told that they feel insecure in the campus, but they could not tell about this to others, because they think that they are indigenous. Although $78 \%$ respondents did not face any problem with their language, $22 \%$ respondents faced problem with it. As an indigenous student $84 \%$ of the respondents did not face any problem in their classes, but $16 \%$ of the respondents told that they faced various problems in their classes. Teachers judge the students irrationally in the academic perspective and $11 \%$ respondents were not satisfied with their teacher's behavior. Though $89 \%$ of the respondents considered that teacher's attitude to them was positive.

It was observed that $82 \%$ respondents passed their leisure time with their electronic devices such as smartphone, radio, television or computer. $2 \%$ used to watch movie in the cinema hall, but $16 \%$ kept them involved with other extracurricular activities. 


\section{Macrothink}

There were 32 respondents who told that there were positive impacts of surrounding atmosphere to their educational life. Among the respondents 25 wished to take the Bangladesh Civil Service as their carrier in future, whereas 16 participants desired for private job. Only 3 respondents wished to be teacher and 1 wanted to be a banker.

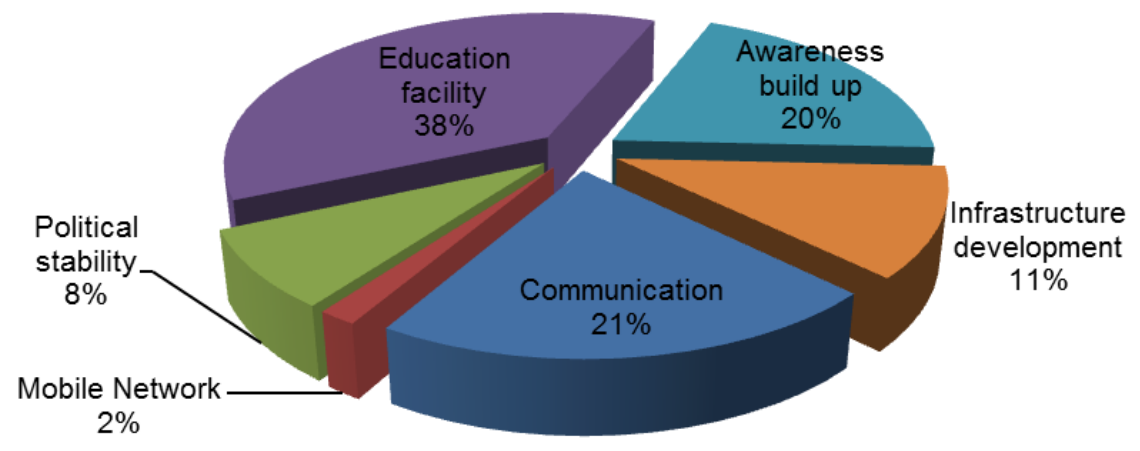

Figure 4. Opinions given by the indigenous students of the University of Dhaka to improve their socio-economic conditions

In this study six types of opinion were noted from the indigenous students regarding the improvement of their socio-economic status, which may influence their academic life. Those were (i) improvement of the communication with their own district, because of which they were deprived of getting available facilities, (ii) extension of the mobile network in their local regions to communicate with others, (iii) stability of the political condition for sustainable development, (iv) enhancement of the educational facilities, (v) awareness build up, and (vi) infrastructure development. A large portion of them (38\%) emphasized on improving the educational facilities. $21 \%$ response came for the communication, $20 \%$ responded about awareness build up, $11 \%$ for infrastructure development, $8 \%$ responded about political stability and $2 \%$ conferred for the mobile network.

\section{Conclusions}

In the society, peoples are becoming aware of necessity and the problems of the indigenous groups. Most of the Aboriginal students came from the lower income group. They faced various problems to adjust with the diverse culture of the university. Sometimes they had to face problem in language, in playing their religious activities or with their food. In addition, they faced problem with their accommodation. Government and university authority should play a vital role for giving them proper rights and in fulfillment of their needs.

\section{Recommendations}

- Students come to the University of Dhaka from different cultures. So every student should be respectful to other's culture and religious views. As the indigenous are the disadvantaged group of our society, we should take special care of their culture and life style. 


\section{Macrothink Institute ${ }^{\mathrm{TM}}$}

- The university authority should take necessary steps to solve the problems of the indigenous students, so that they can easily cope up and feel safe in the advanced culture and tradition of the students of other society. The authority can manage special accommodation and study facilities for them in the university.

- The opinion came from the indigenous students about their need should be implemented in priority basis.

- The government should provide equal opportunity to all, especially in the case of jobs, land and property.

- Endurance should be increased for activities, cultural and religious views, traditional customs and foods.

- Awareness should be build-up for the removal of the racial discrimination.

\section{Acknowledgement}

The author would like to acknowledge the assistance of the Institute of Social Welfare and Research (ISWR), University of Dhaka, and Dr. Tania Rahman of ISWR for her supports during the survey of this research.

\section{References}

Alam, G. M. (2009). The Role of Science and Technology Education at Network Age Population for Sustainable Development of Bangladesh Through Human Resource Advancement. Scientific Research and Essays, 4(11), 260-1270.

Andersen, C., Bunda, T., \& Walter, M. (2008). Indigenous Higher Education: The Role of Universities in Releasing the Potential. The Australian Journal of Indigenous Education, 37(1), 1-8. https://doi.org/10.1375/S1326011100000041

Baral, B. D., \& Das, J. P. (2004). Intelligence: What is Indigenous to India and What is Shared? In R. J. Sternberg (Ed.), International handbook of intelligence (pp. 270-301). New York: Cambridge University Press. https://doi.org/10.1017/CBO9780511616648.010

Barkat, A., et al. (2009). Socio-economic baseline survey of Chittagong hill tracts. HDRC, UNDP Bangladesh.

BBS. (2014). Bangladesh Population and Housing Census 2011, National Report, Vol-3: Urban Area Report.

Besra L., (2006). The rights on Land and the Existence of Adivasi in North Bengal, Journal of Ethnic Affairs, 2, 40-41.

Conway, R. (2006). Students with Emotional and Behavioral Disorders: an Australian Perspective. Preventing School Failure, 52(2), 15-20. http://dx.doi.org/10.3200/PSFL.50.2.15-20

Graham, L. J. (2012). Disproportionate Over-representation of Indigenous Students in New South Wales Government Special Schools. Cambridge Journal of Education, 42(2), 163-176. 
http://dx.doi.org/10.1080/0305764X.2012.676625

Haque, Z. (2000). The Ethnic Minority 'Underachieving' Group? Investigating the Claims of 'Underachievement' Amongst Bangladeshi Pupils in British Secondary Schools. Race Ethnicity and Education, 3(2), 145-168. http://dx.doi.org/10.1080/13613320050074014

Maloney, C. T. (1984). Tribes of Bangladesh and synthesis of Bengali culture. In M. S. Qureshi (Ed.), Tribal Cultures in Bangladesh (pp. 5-52). Rajshahi: Institute of Bangladesh Studies.

Malcolm, I. G., \& Rochecouste J. (2002). Barriers to Indigenous Student Success in Higher Education. Paper presented at Quality Conversations: HERDSA Conference, Perth, Australia: July 7-10, 2002.

Miller, B. D. (2005). Cultural anthropology. (3rd ed.). Boston: Allyn and Bacon.

Roy, R. C. (2000). Land rights of the indigenous peoples of the Chittagong hill tracts, Bangladesh. Denmark: IWGIA.

Schendel, W. V. (2009). A History of Bangladesh. Cambridge: Cambridge University press. https://doi.org/10.1017/CBO9780511997419

Sanders, D. (1999). Indigenous Peoples: Issues of Definition. International Journal of Cultural Property, 8, 4-13. https://doi.org/10.1017/S0940739199770591

Usher, K., Lindsay, D., Miller, M., \& Miller, A. (2005). Challenges Faced by Indigenous Nursing Students and Strategies that Aided their Progress in the Course: A Descriptive Study, Contemporary Nurse, 19, 1-2. http://dx.doi.org/10.5172/conu.19.1-2.17

\section{Glossary}

BBS: Bangladesh Bureau of Statistics.

BDT: Bangladeshi Taka.

HERDSA: Higher Education Research and Development Society of Australasia.

HDRC: Human Development Resource Centre.

IWGIA: International Work Group for Indigenous Affairs.

UNDP: United Nations Development Programme.

\section{Copyright Disclaimer}

Copyright reserved by the author(s).

This article is an open-access article distributed under the terms and conditions of the Creative Commons Attribution license (http://creativecommons.org/licenses/by/3.0/). 